\title{
Evolutionary Medicine: A Key to Introducing Evolution
}

\author{
W. Eric Meikle • Eugenie C. Scott
}

Published online: 2 December 2011

(C) Springer Science+Business Media, LLC 2011

\begin{abstract}
Science teachers can use examples and concepts from evolutionary medicine to teach the three concepts central to evolution: common descent, the processes or mechanisms of evolution, and the patterns produced by descent with modification. To integrate medicine into common ancestry, consider how the evolutionary past of our (or any) species affects disease susceptibility. That humans are bipedal has produced substantial changes in our musculoskeletal system, as well as causing problems for childbirth. Mechanisms such as natural selection are well exemplified in evolutionary medicine, as both disease-causing organism and their targets adapt to one another. Teachers often use examples such as antibiotic resistance to teach natural selection: it takes little alteration of the lesson plan to make explicit that evolution is key to understanding the principles involved. Finally, the pattern of evolution can be illustrated through evolutionary medicine because organisms sharing closer ancestry also share greater susceptibility to the same disease-causing organisms. Teaching evolution using examples from evolutionary medicine can make evolution more interesting and relevant to students, and quite probably, more acceptable as a valid science.
\end{abstract}

Keywords Evolution · Evolution education - Natural selection · Phylogeny · Human reproduction · Disease . Antievolutionism

Evolution is a three-part concept. The keystone of evolution is common descent: living things have descended with modification from common ancestors. This first part constitutes the

W. E. Meikle $(\bowtie) \cdot$ E. C. Scott

National Center for Science Education,

Berkeley, CA, USA

e-mail: meikle@ncse.com "what happened" of evolution. Second, there are the mechanisms through which common descent occurs: natural selection, mutation, genetic drift, speciation, and so on. These constitute the processes of evolution. The third part of the idea of evolution is the pattern generated by descent with modification, how the tree of life has branched over time. The pattern of evolution reflects the relationships among all living things, with closer genetic similarity found among those organisms sharing more recent common ancestry, and less close genetic similarity among those more distantly related.

Unsurprisingly, the new field of evolutionary medicine turns out to be relevant to all three components of evolution. We suggest that teachers consider starting discussions of evolution with a medical example, and use such topics throughout their teaching in order to stimulate student interest and provide real-life examples that can hit home. For each of the three components of evolution, we suggest a few possible examples below, but these are by no means the only such topics. Many aspects of medicine, such as cancer, antibiotic resistance, genetic diseases, aging, and emerging diseases, are also included within evolutionary medicine, and any of these, as well as the evolutionary history of human anatomy and physiology could be pressed into service in the classroom.

Students interested in a career in medicine may find these examples especially compelling. In recent years, there have been increasing calls for more evolution to be taught in medical schools to make explicit the connections with evolutionary biology that have often been neglected in medical education (Nesse et al. 2006, 2010). Any modifications of medical school requirements may be expected to result in changes at the undergraduate curriculum level and ultimately to affect pre-college education as well. Some college biology textbooks already include material 
about medicine and evolution (e.g., Hillis et al. 2010; Zimmer 2010).

\section{Common Descent}

Living things have histories - they have descended with modification from common ancestors. As such, every species reveals evidence of its past in its morphology, its genetics, its biochemistry, and its behavior. The first chapter of Darwin's The Descent of Man (1871) is, while dated, still a good source of examples in the case of humans, as is Neil Shubin's Your Inner Fish (2008). And of course there are examples at the genetic as well as the morphological level (e.g., Gerstein and Zheng 2006).

The diseases that an organism exhibits similarly reflect its evolutionary history. For example, humans are unique in being bipedal primates: no other primate habitually walks erect. Bipedalism has produced distinctive changes in the human skeleton that have significant consequences for muscular and skeletal conditions. There are reasons why humans have so many complaints about lower back and knee pain. The weight of a quadrupedal animal-a "walking bridge"-is borne by both the shoulder and pelvic girdles, whereas all of the weight of a bipedal primate has to pass through the pelvis to the legs. To keep the upper body weight balanced, the spine has to curve back upon itself (forming an "S" shape). The lumbar vertebral region of humans, therefore, is subject to stresses not encountered by quadrupeds like apes and monkeys, too often resulting in lower back pain. This is not an inconsequential illness: in the U.S., lower back pain is said to be suffered by $80 \%$ of adults at some time or another. And many young students are warned - rightly—not to carry heavy backpacks across one shoulder, risking muscle strain and spinal injury.

Similarly, in a quadruped, the weight of the viscera more or less rests evenly along the abdominal muscles, supported by mesenteries running from the dorsal side of the abdominal cavity. In a biped, the viscera are tipped, which means there is more opportunity for them to bulge through the muscles of the abdominal wall, forming painful hernias.

But perhaps the most serious medical consequence of our bipedal evolution is that changes in the pelvis required for bipedalism make childbirth very difficult. The shape of the pelvis in humans reflects the biomechanical needs of bipedalism (Rosenberg and Trevathan 2005). The upper bone of the pelvis, the ilium, is shortened and broadened, and other pelvic bones are modified to transfer the full weight of the upper body down the spine and the sacrum to the femur, and to bring muscles into position to move the legs efficiently during walking and running. All of these postural and locomotor adaptations result in changes to the size and shape of the birth canal, which has obvious effects on the delivery of the fetus. In a normal birth, the fetus has to rotate twice-first to get the head and second the shoulders into position to pass through the birth canal. That's if everything goes well, and of course, it doesn't always. Archeological records regularly show that for most pre-industrial populations, the highest mortality for women is in the prime child-bearing years of 15-35. Combine a tight birth canal with a large-brained fetus, and these are not surprising statistics.

These are examples of how just one feature of human evolution-bipedalism - affects health and disease. Other examples exist as well, of course: the nutritional requirements of humans are a result of our evolutionary heritage, much of which was spent as hunter-gatherers. The advent of agriculture changed those selection pressures, causing new diseases, and post-industrial dietary changes have created yet newer ones. A discussion can be found in Trevathan (2007) and references therein.

\section{Mechanisms of Evolution}

Perhaps the easiest and most obvious way to bring medicine into evolution is by discussing the mechanism of natural selection at work in pathogens. Especially in microorganisms with a short generation span, examples of natural selection in action abound. The Understanding Evolution website offers resources on antibiotic resistance (http://evolution.berkeley. edu/evolibrary/article/medicine_03), the human immunodeficiency virus (http://evolution.berkeley.edu/evolibrary/ article/0_0_0/medicine_04), and methicillin-resistant Staphylococcus aureus (MRSA) (http://evolution.berkeley.edu/ evolibrary/news/080401_mrsa). Sometimes there may even be the chance to make the lesson emphatically topical: Cook (2009) describes the development of a unit on evolution prompted by a local outbreak of MRSA.

But it's not necessary to think small. From television advertisements and drugstore shelves, students will no doubt be familiar with lactose intolerance, the inability to digest milk products after the age of five or so. Will they know, however, that the bulk of the world's population lacks the lactase persistence gene that enables a few to digest milk products into adulthood? And will they know, moreover, that there are interesting patterns in the geographical distribution of the lactase persistence gene (Bersaglieri et al. 2004)? Present them with a challenge: what evolutionary mechanisms might be responsible? In order to make sense of the distribution of lactase persistence, students will have to apply plenty of what they've learned about mutation, selection, drift, and migration, as well as to make a bit of a foray into advanced ideas such as gene-culture coevolution (Beja-Pereira et al. 2003). Understanding Evolution discusses teaching about 
lactose evolution (http://evolution.berkeley.edu/evolibrary/ news/070401_lactose).

\section{Patterns of Evolution}

Susceptibility to diseases can reflect phylogeny. Closely related species share similarities beyond the familiar anatomical, physiological, biochemical, and behavioral ones: they also tend to fall prey to similar diseases. For example, foot-and-mouth disease is widespread among artiodactyls, but not other mammals. Closer to home, humans and other apes are susceptible to many of the same viruses and bacteria. Keeping captive primates safe from airborne human diseases is one reason why well-run zoos put glass barriers between their occupants and visitors. A recent online report in The Scientist (http://the-scientist. com/2011/10/01/gorilla-warfare/) discusses transmission of a human viral respiratory disease to gorillas living in the wild, warning, "with ecotourism on the rise, more and more foreign visitors travel to see wild animals up close and personal, increasing the risk of disease transmission." Your pet dog, on the other hand, has little to fear from your influenza virus: dogs are much more distantly related to humans than are apes.

Disease-causing organisms have phylogenies too. Using genetic and molecular comparisons, researchers are able to trace the evolution of pathogens and parasites. One example that is sure to interest high school students (and middle school students even more) involves human lice. There are two subspecies of louse that infest humans, the body louse Pediculus humanus corporis and the head louse Pediculus humanus capitis, which have a variety of morphological, behavioral, and ecological differences corresponding to their different habitats. They diverged from their common ancestor after human beings began to lose their body hair and to adopt the use of clothing. So scientists have managed to use a molecular clock approach on the genomes of lice to estimate when humans might have begun to use clothing (e.g., Kittler et al. 2003; Toups et al. 2011). (A short video discussing implications of using lice to understand aspects of human evolution is available online from NOVA: http://www.pbs.org/wgbh/nova/evolution/lice. $\mathrm{html}$, and a lesson plan on lice and human evolution is available from the National Center for Case Study Teaching in Science: http://sciencecases.lib.buffalo.edu/cs/collection/ detail.asp?case $\mathrm{id}=488 \& \mathrm{id}=488$.)

\section{Conclusion}

So are examples from medicine likely to aid the effective teaching of evolution? On the one hand, there is reason to believe that people are more likely to accept the idea of evolution and its importance in science when it is linked to practical applications. In particular, recognizing the contribution of evolution to the medical sciences may make people more likely to understand why it should be a part of the science curriculum. At least one poll (Coalition of Scientific Societies 2008) suggests that highlighting the medical applicability of evolution is a winning strategy: "Among a sample of respondents, 61\% thought that understanding the contribution that evolution makes to modern medical science, including understanding and treating diseases such as avian influenza, was a convincing reason to teach evolution in science classes."

On the other hand, there is reason, to be found in public opinion polls and anecdotes alike, to believe that people are more likely to reject the idea of evolution and its importance in science when they are thinking of human evolution in particular. This aversion is doubtless reflected in state science standards, only seven of which provide a comprehensive treatment of human evolution (Mead and Mates 2009), and in the individual classroom, where $17 \%$ of public school high school biology teachers omit human evolution altogether and $60 \%$ spend five hours or less on the topic (Berkman et al. 2008). Is there a risk, then, that introducing examples from medicine in the teaching of evolution will in fact be counterproductive, by reminding students that evolution applies to humans as well as to the rest of the living world?

Our view - and our hope - is that the risk is minimal. It seems likely that part of the reason for the rejection of human evolution in particular is the idea that evolution only concerns the past, that it is about fossils and ancient events, with no real relevance to people today. (Part, but only part: ideas about human exceptionalism related to religious belief obviously play a role as well.) Approaching human evolution solely through the paleoanthropological record reinforces that mistaken idea, and also invites the expression of a familiar if equally mistaken skepticism about the adequacy of the fossil record. Adding a careful exposition of how evolution informs medical practice and researchthe same medicine that students can see at work healing the wounded, preparing cures, and devising remedies-will help not only to convey the power and beauty of evolution in general but also to assuage qualms about human evolution in particular.

\section{Resources}

Understanding Evolution

Relevance of Evolution: Medicine

http://evolution.berkeley.edu/evolibrary/article/0_0_0/ medicine_01 
NIH Curriculum Supplements for High School

Evolution and Medicine

http://science-education.nih.gov/customers.nsf/HSE

volution.htm

Henry Stewart Talks

Evolution and Medicine: How New Applications Advance Research and Practice

http://hstalks.com/main/browse_talks.php?father_id= $20 \& c=252$

Acknowledgments We thank Glenn Branch for substantial discussion and comments.

\section{References}

Beja-Pereira A, Luikart G, England PR, Bradley DG, Jann OC, Bertorelle $\mathrm{G}$, et al. Gene-culture coevolution between cattle milk protein genes and human lactase genes. Nat Genet. 2003;35:311-3.

Berkman MB, Pacheco JS, Plutzer E. Evolution and creationism in America's classrooms: a national portrait. PLoS Biol. 2008;6(5):e124.

Bersaglieri T, Sabeti PC, Patterson N, Vanderploeg T, Schaffner ST, Drake JA, et al. Genetic signatures of strong recent positive selection at the lactase gene. Am J Hum Genet. 2004;74:1111-20.

Coalition of Scientific Societies. Evolution and its discontents: a role for scientists in science education. FASEB J. 2008;22:1-4.
Cook K. A suggested project-based evolution unit for high school: teaching content through application. Am Biol Teach. 2009;71:95-8.

Darwin CR. The descent of man. London: John Murray; 1871.

Gerstein M, Zheng D. The real life of pseudogenes. Sci Am. 2006;295 (2):48-55.

Hillis DM, Sadava D, Heller HC, Price MV. Principles of life. Sunderland: Sinauer Associates; 2010.

Kittler R, Kayser M, Stoneking M. Molecular evolution of Pediculus humanus and the origin of clothing. Curr Biol. 2003;13:1414-7.

Mead LS, Mates A. Why science standards are important to a strong science curriculum and how states measure up. Evol Educ Outreach. 2009;2:359-71.

Nesse RM, Stearns SC, Omenn GS. Medicine needs evolution. Science. 2006;311:1071.

Nesse RM, Bergstrom CT, Ellison PT, Flier JS, Gluckman P, Govindaraju DR, et al. Making evolutionary biology a basic science for medicine. Proc Natl Acad Sci (USA). 2010;107 suppl 1:1800-7.

Rosenberg K, Trevathan W. Bipedalism and human birth: the obstetrical dilemma revisited. Evol Anthropol. 2005;4(5):161-8.

Shubin N. Your inner fish: a journey into the 3.5-billion-year history of the human body. New York: Pantheon; 2008.

Toups MA, Kitchen A, Light JE, Reed DL. Origin of clothing lice indicates early clothing use by anatomically modern humans in Africa. Mol Biol Evol. 2011;28:29-32.

Trevathan W. Evolutionary medicine. Annu Rev Anthropol. 2007;36:139-54.

Zimmer C. The tangled bank: an introduction to evolution. Greenwood Village: Roberts and Company; 2010. 